\title{
RELATIONSHIP OF DENTAL CARIES AND FLUOROSIS TO FLUORIDE SUPPLEMENT HISTORY IN A NON- FLUORIDATED SAMPLE OF SCHOOLCHILDREN
}

\author{
R.A. BAGRAMIAN ${ }^{1}$, S. NARENDRAN ${ }^{2}$, AND M. WARD ${ }^{2}$ \\ The University of Michigan, School of Dentistry", School of Public Health ${ }^{2}$, Ann Arbor, Michigan \\ 48109
}

Adv Dent Res 3(2): 161-167, September, 1989

\begin{abstract}
A random sample of 206 Michigan children, aged from 9 to 13, were examined for fluorosis from a larger group of 2038 children participating in a dental project. Clinical examinations included caries data (DMFS) and assessment of fluorosis by use of the Tooth Surface Index of Fluorosis (TSIF). Separate examiners were used for each index. The response rate of a questionnaire mailed to parents to gather information on residence histories, use of fluoride supplements, and antibiotics was $78 \%$. The prevalence of fluorosis was about $20 \%$ among the respondents. Of the 4868 tooth surfaces examined, $9.2 \%$ were affected by fluorosis. In all cases, dental fluorosis was judged as mild, with most occurrences on the posterior teeth. No instances of moderate or severe fluorosis were found. The caries experience of respondents was 1.69 \pm 2.73 DMFS. Caries experience does not appear to be significantly related to income, education, or fluoride supplement use. Approximately $52 \%$ of respondents were reported to have taken fluoride supplements with various degrees of consistency. Parents' education was positively related to both prevalence of fluorosis (odds ratio $=2.2$ ) and use of fluoride supplements (odds ratio $=2.7$ ). No significant relation was revealed with evidence of fluorosis and use of supplements. This study shows a relatively mild level of dental fluorosis in a sample of children from a non-fluoridated area. Dental fluorosis in this group does not appear to be related to use of fluoride supplements or differences in caries experience.
\end{abstract}

\section{INTRODUCTION}

The use of fluoride as a caries-preventive measure has been an accepted procedure since the early studies of Dean et al. (1950). Fluorides exert both systemic and topical effects in cariostasis, and the topical effect appears to be the predominant of the two modes of action (Ericsson, 1977; Fejerskov et al., 1981; Levine, 1976). The systemic effect, however, may still play an important role in the prevention of dental caries in fluoride-deficient communities. A decline in dental

Presented at the Symposium and Workshop on Developmental Defects of Enamel, February 23-25, 1988, Rotorua, New Zealand, sponsored by Colgate-Palmolive (NZ) Ltd., the New Zealand Dental Research Foundation, and the Medical Research Council of New Zealand caries has been observed in children in developed nations over the last 20 years (Anderson et al., 1982; Brown, 1982; Brunelle and Carlos, 1982). Increased availability of fluorides from various sources was cited as one of the possible causes for this decline in dental caries (DePaola et al., 1982). Concern has been raised that an increased availability of fluorides could result in greater prevalence and severity of dental fluorosis (Leverett, 1982).

As a result, interest in dental fluorosis has increased during the last few years (Leverett, 1982; Segreto et al., 1984; Horowitz et al., 1984; Driscoll et al., 1986). Chronic endemic dental fluorosis is a hypoplasia or hypomineralization of enamel that can range in appearance from light white striations of a small area to dark brown stain affecting the entire crown. Few studies have attempted to assess dental fluorosis 
in fluoride-deficient communities. The prevalence of dental fluorosis in permanent dentition among fluoride-deficient communities has been reported to range from 2.9\% for 8-16-year-olds (Driscoll et al., 1986) to $22 \%$ for 6-8-year-olds (Oldak and Leverett, 1984).

Several studies have examined the prevalence of dental fluorosis in relation to use of fluoride supplements. Fluoride supplementation has been associated with lower caries prevalence and increased evidence of dental fluorosis (Anderson and Grahnén, 1976; Hennon et al., 1977; Aasenden and Peebles, 1978; Thylstrup et al., 1979; Larsen et al., 1985; Soparkar and DePaola, 1985). Suckling and Pearce (1984) detected an association between "developmental defects" and exposure to either fluoridated water or fluoride tablets in a sample of 12-14-year-old children. The relation between fluoride supplements and dental fluorosis in fluoride-deficient communities has not been widely investigated. The purpose of this study was to assess the effects of fluoride supplementation of dental caries and dental fluorosis in a sample of elementary schoolchildren in a fluoridedeficient community.

\section{MATERIALS AND METHODS}

The study population consisted of 206 elementary schoolchildren, aged $9-13$ years, who were randomly selected from an ongoing larger dental project in a fluoride-deficient area. The group consisted of $50.9 \%$ boys and $49.1 \%$ girls. Subjects were examined for dental caries and dental fluorosis by two separate examiners to minimize examiner bias. Only permanent teeth were examined for the purpose of this study. Missing primary teeth with no permanent successors were recorded as unerupted permanent teeth. Data were entered directly into microcomputers by means of appropriate software.

Dental caries was recorded using the Decayed, Missing, and Filled Surfaces (DMFS) index. Diagnostic criteria for dental caries were those developed by Radike (1968). Softness or a definite break in continuity of enamel was a prerequisite for a tooth to be considered carious. Missing teeth were classified, by the examiner, after an assessment of the child's dental condition. Radiographs were not exposed.

Fluorosis was assessed by the Tooth Surface Index of Fluorosis (TSIF) (Horowitz et al., 1984). Differential diagnoses between nonfluoride opacities and fluorosis were based on criteria developed by Russell (1961). The extent of the affected enamel is determined by estimation of the amount of fluorosis as a fraction of the total visible enamel surface. TSIF gives a separate score to each unrestored tooth surface. According to TSIF, two surfaces (buccal and lingual) in anterior teeth and three in posterior teeth (buccal, lingual, and occlusal) are examined for fluorosis. TSIF measures severity of fluorosis in different tooth surfaces.
A self-administered mail questionnaire was developed and pre-tested so that we could collect data on the use of fluoride supplements, frequency of supplement use, and age at which supplement use began and stopped. Information was also sought on oral hygiene practices, dental visits, and exposure to other sources of fluorides. In addition, data were collected on demographic characteristics of parents of study participants, and included levels of income, education, and ethnicity. The questionnaire was constructed of three open-ended and 23 pre-coded questions. Two mailings were done to improve response rate. Relevant responses to open-ended questions were coded before data were analyzed.

Statistical analyses were carried out in the Michigan Terminal System (MTS) by use of the Statistical Package for the Social Sciences, SPSS. Since distribution of DMFS scores was not normal, a nonparametric test (the Mann-Whitney $U$ test) was applied for assessment of the differences in DMFS scores among subjects stratified by fluoride supplement use, parents' income, and education. Chi-square tests of association and prevalence odds ratios were used for assessment of differences in distribution of dental fluorosis in different subgroups of respondents. Prevalence odds ratios estimate the probability of a condition (fluorosis) between groups with different attributes (such as high or low income) and those who took supplements regularly or irregularly. An odds ratio of one (unity) indicates a lack of association between the two groups under study. Odds ratios are defined as the ratio of odds. Prevalence odds ratio denotes an odds ratio computed from a cross-sectional study which utilizes prevalent cases and not incident cases. In this study, the prevalence odds ratio is the ratio of odds in favor of a condition (fluorosis) among those with a certain attribute (high income/education) to the odds in favor of the condition in those with a contrasting attribute (low income/ education). Prevalence odds ratios were computed by use of a $2 \times 2$ contingency table. Thus, only one attribute was assessed each time for its association with an outcome (fluorosis/fluoride supplementation). But in presentation of the results, either two or three different attributes were shown in the same Table $(7,8,9)$ for convenience.

Children residing in a household whose reported income was greater than $\$ 18,000$ were considered as the high group, and children in households with incomes less than $\$ 18,000$ were considered in the lowincome group. Children with either parent possessing a college degree were categorized as members of the high-education group, and children of parents without a college degree were assigned to the loweducation group. Those children who reportedly took fluoride supplements daily were grouped as regular users of fluoride supplements and those who did not recall taking supplements daily as irregular users. Not all respondents answered all questions from the survey instrument. Such non-response resulted in miss- 
ing data related to certain variables, such as income and frequency of supplementation. Thus, in Tables 8 and 9 , the total number of children does not add up to 159 , due to missing data.

RESULTS

Two mailings resulted in 161 questionnaires being returned by parents - a response rate of $78 \%$. Demographic and dental characteristics of children of respondents and nonrespondents are shown in Tables 1 and 2, respectively. The age distributions of both groups are comparable, but a difference in gender distribution between the two groups did exist. Dental caries (1.69 DMFS for respondents vs. 1.71 DMFS for nonrespondents) and dental fluorosis experience (90.6\% vs. $95.8 \%$ fluorosis-free) were almost similar, thus ruling out any response bias to the survey. Respondents appear to be an homogeneous group in relation to ethnicity, with about $99 \%$ Caucasians. Children of two respondents who were not Caucasians were excluded from statistical analyses in order to maintain homogeneity of the study population. Results presented in this paper relate to findings from 159 respondents.

Among respondents to the mail survey, 52\% reported giving supplements to their children, while $48 \%$ did not. About $69 \%$ of parents who gave supplements claimed to do it "daily", while $31 \%$ claimed to do it on an irregular basis. Use of fluoride supplements was related to parents' education but not to levels of income (Table 3). Parents with a college degree are 2.2 times more likely to give fluoride supplements to their children than are parents without a college degree (odds ratio $=2.2 ; 95 \%$ confidence interval $=1.13-5.76$ ).

No association was found between frequency of supplement use and either income or education levels of parents within the groups. Regular daily use was not related to income or education among supplement users. About $69 \%$ of parents in the higheducation group reported having given supplements to their children daily, while $67 \%$ in the low-education group did so also. Similarly, $56 \%$ of parents from the high-income group and $51 \%$ from the low-income group reported having given daily fluoride supplements to their children.

Prevalence of dental fluorosis among the respon-
TABLE 1

DEMOGRAPHICS OF RESPONDENTS AND NONRESPONDENTS TO MAIL SURVEY

\begin{tabular}{|c|c|c|c|c|}
\hline & \multicolumn{2}{|c|}{ Respondents } & \multicolumn{2}{|c|}{$\begin{array}{l}\text { Non- } \\
\text { respondents }\end{array}$} \\
\hline & $(\%)$ & $N$ & $(\%)$ & $\mathrm{N}$ \\
\hline \multicolumn{5}{|l|}{ Gender } \\
\hline Male & 55.9 & 90 & 35.6 & 16 \\
\hline Female & 44.1 & 71 & 64.4 & 29 \\
\hline \multicolumn{5}{|l|}{ Age } \\
\hline 9 years & 13.7 & 22 & 13.3 & 6 \\
\hline 10 years & 38.5 & 62 & 31.1 & 14 \\
\hline 11 years & 29.2 & 47 & 33.3 & 15 \\
\hline 12 years & 17.4 & 28 & 17.8 & 8 \\
\hline 13 years & 1.2 & 2 & 4.4 & 2 \\
\hline
\end{tabular}

dents was $19.9 \%$. Of 5362 tooth surfaces examined, only about $9 \%$ were affected by fluorosis, and approximately $91 \%$ of surfaces were free of fluorosis (Table 4). Those surfaces diagnosed with fluorosis were very mildly affected, having scores of $\leq 2$ on the TSIF scale. Dental findings of both respondents and nonrespondents have already been reported (Narendran et al., 1987).

No significant relations were found between use of supplements and evidence of dental fluorosis. The relation between prevalence of dental fluorosis and levels of income, education, and frequency of fluoride supplement use is shown in Table 5. An interesting finding was an increase in use of supplements with a concomitant increase in dental fluorosis for those children whose parents had higher levels of education. A significant association was observed between dental fluorosis and education level of the head of household (odds ratio $=2.7 ; 95 \%$ confidence interval $=1.29$ to 5.73). A child with at least one parent who was a college graduate was 2.7 times as likely to have fluorosis as was a child with parents who did not have college degrees.

Table 6 shows the relation between prevalence of fluorosis and the corresponding ages at which children started (as well as ages at which children stopped) taking fluoride supplements. A slightly positive but not significant association was observed between prevalence of dental fluorosis and frequency of fluoride supplement use. Those children who reportedly

TABLE 2

DENTAL CARIES AND FLUOROSIS OF RESPONDENTS AND NON-RESPONDENTS TO THE SURVEY

\begin{tabular}{lcr}
\hline Characteristic & Respondents $(\mathrm{N}=159)$ & Non-respondents $(\mathrm{N}=45)$ \\
\hline Fluorosis by children & $19.9 \%$ & $14.5 \%$ \\
Fluorosis by surfaces & $9.2 \%$ & $4.6 \%$ \\
Prevalence of Dental Caries & $50.3 \%$ & $55.3 \%$ \\
Severity of Dental Caries (DMFS) & $1.69 \pm 2.73$ & $1.71 \pm 2.35$ \\
\hline
\end{tabular}


TABLE 3

ASSOCIATION BETWEEN SYSTEMIC FLUORIDE SUPPLEMENTS AND PARENTS' LEVELS OF EDUCATION AND INCOME

\begin{tabular}{lcccc}
\hline & $\begin{array}{c}\text { Supplements } \\
(\%)\end{array}$ & $\begin{array}{c}\text { No Supplements } \\
(\%)\end{array}$ & $\begin{array}{c}\text { Odds Ratio } \\
(\text { OR })\end{array}$ & $\begin{array}{c}95 \% \text { Confidence } \\
\text { Interval of OR }\end{array}$ \\
\hline $\begin{array}{l}\text { Parents' Education } \\
\quad \text { College Graduate }\end{array}$ & 59.4 & 40.6 & & \\
$\quad$ College & 40.1 & 59.9 & $2.2^{*}$ & $1.13-5.76$ \\
$\begin{array}{l}\text { Parents' Income } \\
\quad \$ 18,000\end{array}$ & 67.0 & & & \\
$<\$ 18,000$ & 68.5 & 33.0 & 1.1 & $0.36-3.24$ \\
\hline
\end{tabular}

${ }^{*} \mathrm{p}=0.01$.

TABLE 4

DISTRIBUTION OF TSIF SCORES FOR ALL PERMANENT TOOTH SURFACES $(\mathrm{N}=159)$

\begin{tabular}{lccc}
\hline & \multicolumn{3}{c}{ Score } \\
\cline { 2 - 4 } & 0 & 1 & 2 \\
\hline Percent & 90.8 & 8.9 & 0.3 \\
No. of Surfaces & 4868 & 476 & 18 \\
\hline
\end{tabular}

started taking supplements before age one had slightly more fluorosis than those who started taking supplements after their first birthday. This association between the age at which children were reported by parents to have started taking fluoride supplements and prevalence of dental fluorosis was significant at the 0.1 level but not the 0.05 level. The distribution of TSIF scores among those who took fluoride supplements regularly and irregularly and those who never took fluoride supplements is shown in Table 7. Those children who used supplements regularly had $14 \%$ of surfaces diagnosed with fluorosis, com- pared with $8.5 \%$ of surfaces for children who never used supplements.

The prevalence of dental caries was found to be $50.3 \%$ with a mean caries severity score of $1.69 \pm 2.73$ Decayed, Missing, and Filled surfaces. Thus, $49.7 \%$ of the children were caries-free. The severity of dental caries among groups stratified by income and education is presented in Table 8. Mean DMFS scores for children of the high-income and high-education group were less than those for the low-income and loweducation group, but differences in DMFS scores were not statistically significant. Dental caries experience for those who reportedly took supplements regularly, irregularly, and never is shown in Table 9. Although not significant, regular users of fluoride supplements had lower DMFS scores than did irregular users and those who never used supplements.

\section{DISCUSSION}

The use of various forms of fluorides is strongly advocated by the dental profession. These modes of

TABLE 5

PREVALENCE OF FLUOROSIS (ODDS RATIO) IN RELATION TO FREQUENCY OF SUPPLEMENT USE, PARENTS' EDUCATION, AND INCOME LEVELS

\begin{tabular}{lcccc}
\hline & $\begin{array}{c}\text { Fluorosis } \\
(\%)\end{array}$ & $\begin{array}{c}\text { No Fluorosis } \\
(\%)\end{array}$ & $\begin{array}{c}\text { Odds Ratio } \\
(\text { OR })\end{array}$ & $\begin{array}{c}\text { 95\% Confidence } \\
\text { Interval of OR }\end{array}$ \\
\hline $\begin{array}{l}\text { Parents' Education } \\
\quad \text { College Graduate }\end{array}$ & 49.5 & 50.5 & & \\
$\quad<$ College & 26.6 & 73.4 & $2.7^{*}$ & $1.29-5.73$ \\
$\begin{array}{l}\text { Parents' Income } \\
\quad \geq \$ 18,000\end{array}$ & 68.5 & 31.5 & & \\
$\quad<\$ 18,000$ & 66.7 & 33.3 & 0.91 & $0.31-2.76$ \\
$\begin{array}{l}\text { Frequency of Supplement Use } \\
\quad \text { Daily }\end{array}$ & 46.4 & 53.6 & & \\
$\quad$ Not Daily & 37.8 & 61.2 & 2.01 & $0.71-5.75$ \\
\hline
\end{tabular}

${ }^{*} \mathrm{p}=0.002$. 
TABLE 6

FLUOROSIS (ODDS RATIO) IN RELATION TO CHILD'S AGE WHEN FLUORIDE SUPPLEMENT USE COMMENCED AND WAS DISCONTINUED

\begin{tabular}{|c|c|c|c|c|}
\hline & $\begin{array}{c}\text { Fluorosis } \\
(\%)\end{array}$ & $\begin{array}{c}\text { No Fluorosis } \\
(\%)\end{array}$ & $\begin{array}{l}\text { Odds Ratio } \\
\text { (OR) }\end{array}$ & $\begin{array}{l}95 \% \text { Confidence } \\
\text { Interval of OR }\end{array}$ \\
\hline \multicolumn{5}{|c|}{ Age when Commenced } \\
\hline$<1$ year & 43.8 & 56.2 & \multirow{2}{*}{1.85} & \multirow{2}{*}{$0.46-7.67$} \\
\hline$>1$ year & 31.0 & 69.0 & & \\
\hline \multicolumn{5}{|c|}{ Age when Discontinued } \\
\hline Still taking & 43.1 & 56.9 & \multirow{2}{*}{1.23} & \multirow{2}{*}{$0.32-4.34$} \\
\hline$<4$ years & 42.4 & 57.6 & & \\
\hline
\end{tabular}

use are several, including water fluoridation, topical fluorides, mouthrinses, toothpastes, and dietary fluoride supplements. Dental health behavior has been studied and reported to follow specific parameters. Kegeles (1963) hypothesized that an increase in level of knowledge about diseases and preventive practices improves attitudes toward health and increases the level of appropriate preventive behavior. Accordingly, better-educated and knowledgeable parents would institute measures to prevent dental caries in their children. The relationship of expected appropriate action is related to socio-economic status, in terms of seeking care and practicing preventive methods (Gift, 1986). A low level of dental diseases has been observed in groups with higher socio-economic status (Clark et al., 1987). The findings in this study confirm this observation, in that respondents to the mail questionnaire demonstrated a significant relation between education of parents and use of fluoride supplements and dental fluorosis in children. One would expect that parents with higher education would be more inclined to use fluoride products such as dietary supplements, toothpaste, and topical applications to reduce dental caries.

Of parents using dietary supplements, $69 \%$ reported giving the supplement daily. This figure is quite high when compared with other studies with prescription medications indicating compliance as low as 30\% (Becker and Maiman, 1980). In addition, Newbrun (1980) reviewed a series of studies conducted with the use of dietary fluoride supplements. He reported a range of compliance figures, with the majority well below $30 \%$. In light of these findings, the results for daily compliance reported here are quite high and could be due to a possible response bias. Since respondents were aware that questionnaires were from members of the dental profession, they might have systematically "overreported" compliance rates.

Dental fluorosis is a developmental defect resulting from incorporation of fluoride in enamel during the process of mineralization. Thus, if an association were to be found between dietary fluoride supplements

TABLE 7

PERCENT DISTRIBUTION OF TSIF SCORES FOR ALL PERMANENT TOOTH SURFACES BY REPORTED USE OF DIETARY FLUORIDE SUPPLEMENTS $(\mathrm{N}=159)$

\begin{tabular}{lccc}
\hline & \multicolumn{3}{c}{ TSIF Score } \\
\cline { 2 - 4 } Supplement Use & 0 & 1 & 2 \\
\hline Daily & 86.7 & 13.0 & 1.0 \\
Not Daily & 89.9 & 10.1 & 0.0 \\
Never & 91.5 & 8.5 & 0.0 \\
\hline
\end{tabular}

TABLE 8

ASSOCIATION BETWEEN DENTAL CARIES AND LEVELS OF PARENTS' EDUCATION AND INCOME

\begin{tabular}{lccc}
\hline & $N^{* *}$ & DMFS & \% Difference \\
\hline Education & & & \\
$\quad$ College Graduate & 91 & 1.45 & 23.7 \\
Less than College & 64 & 1.90 & \\
Income & & 1.56 & 18.8 \\
$\quad \geq 18,000$ & 105 & 1.92 & 0.33 \\
$\leq 17,999$ & 43 & & \\
\hline
\end{tabular}

* Mann-Whitney U test.

** Not all respondents reported income/education. 
TABLE 9

DENTAL CARIES IN RELATION TO FREQUENCY OF FLUORIDE SUPPLEMENT USE

\begin{tabular}{lcccc}
\hline Supplement Use & $\begin{array}{c}\text { Prevalence } \\
(\%)\end{array}$ & $\mathrm{N}^{*}$ & $\begin{array}{l}\text { Severity } \\
\text { (DMFS) }\end{array}$ & $\mathrm{p}$ value** \\
\hline Daily & 50.9 & 56 & $1.56 \pm 2.16$ & 0.27 \\
Not Daily & 65.3 & 26 & $1.88 \pm 2.95$ & 0.40 \\
Never & 55.1 & 68 & $1.71 \pm 3.03$ & \\
\hline
\end{tabular}

* Total does not add up to 159 due to non-responses.

* Mann-Whitney U test.

and dental fluorosis, the supplements should have been administered during the ages at which teeth undergo mineralization. Most permanent teeth found in this study population begin to mineralize at birth and during the first year after birth. The observed positive trend between those who started taking supplements before their first birthday and prevalence of fluorosis confirms this concept. This finding is similar to that of Soparkar and DePaola (1985), who found an association between prescribed supplements and vitamins, especially in children who ingested the tablet form before the age of three.

Although the trend was positive, no significant association was observed between use of dietary fluoride supplements and either caries prevalence or severity. In controlled clinical trials on fluoride supplements, compliance rates are bound to be high, due to supervision. Respondents in this study were administering fluoride supplements to children on their own initiative and lacked the rigorous supervision of controlled trials. Therefore, compliance with the daily regimen of fluoride supplements may not have been adequately high, especially in light of the possible response bias discussed previously.

It is important to point out that no appreciable difference was found in the levels of fluorosis between fluoride supplement users and non-users. The level of fluorosis identified in this population was low, with only about $9 \%$ of all available surfaces or $20 \%$ of children affected. TSIF was used in this study for assessment of fluorosis, and scores of 1-3 on the TSIF scale could be considered similar to the diffuse patchy opacities of the FDI index on developmental defects of enamel (FDI, 1982). Using the latter index, Suckling and Pearce (1984) found the prevalence of diffuse opacities to be $16.5 \%$ in children, similar to the prevalence observed in this study. The FDI index uses a tooth as the unit of interest, in contrast to the tooth surface on the TSIF scale. This unit difference in indices may affect their sensitivities, and could account for the differences in teeth affected in the New Zealand population and surfaces affected in the US population.

In summary, the trend was for parents with high socio-economic status to use dietary fluoride supple- ments for their children to a greater extent. Children who used supplements before one year of age demonstrated higher prevalence of dental fluorosis. Interestingly, regular users of supplements tended to have lower levels of caries. It must be emphasized, however, that most of these trends were not statistically significant and must be viewed carefully. Based on this study, it appears that reported use of dietary fluoride supplements does not have a significant effect on the prevalence of dental fluorosis for this population from a fluoride-deficient area.

\section{REFERENCES}

AASENDEN, R. and PEEBLES, T.C. (1978): Effects of Fluoride Supplementation from Birth on Dental Caries and Fluorosis in Teenaged Children, Arch Oral Biol 23: 111-115.

ANDERSON, R. and GRAHNÉN, H. (1976): Fluoride Tablets in Preschool Children Age - Effect on Primary and Permanent Teeth, Swed Dent / 69: 137-143.

ANDERSON, R.J.; BRADNOCK, G.; BEAL, J.F.; and JAMES, P.M.C. (1982): The Reduction in Caries Prevalence in English Schoolchildren, / Dent Res 61: 1311-1316.

BECKER, M.H. and MAIMAN, L.A. (1980): Strategies for Enhancing Patient Compliance, Commun Health 6: 113-135.

BROWN, R.H. (1982): Evidence of Decrease in the Prevalence of Dental Caries in New Zealand, I Dent Res 61: 1327-1330.

BRUNELLE, J.A. and CARLOS, J.P. (1982): Changes in the Prevalence of Dental Caries in U.S. Schoolchildren, 1961-80, J Dent Res 61: 1346-1351.

CLARK, B.J.; GRAVES, R.C.; WEBSTER, D.B.; and TRIOL, C.W. (1987): Caries and Treatment Patterns of Children Related to School Lunch Program, J Publ Health Dent 47: 134-138.

DEAN, H.T.; ARNOLD, F.A., Jr.; JAY, P.; and KNUTSON, J.W. (1950): Studies on Mass Control of Dental Caries Through Fluoridation of the Public Water Supply, Public Health Reports 65: 14031408.

DePAOLA, P.F.; SOPARKAR, P.M.; TAVARES, M.; ALLUKIAN, M.; and PETERSON, H. (1982): A Dental Survey of Massachusetts Schoolchildren, J Dent Res 61: 1356-1360.

DRISCOLL, W.S.; HOROWITZ, H.S.; MYERS, R.J.; HEIFETZ, S.B.; and KINGMAN, A. (1986): Prevalence of Dental Caries and Dental Fluorosis in Areas with Negligible, Optimal, and Above-optimal Fluoride Concentrations in Drinking Water, I Am Dent Assoc 113: 29-33.

ERICSSON, S.Y. (1977): Cariostatic Mechanism of Actions of Fluorides: Clinical Observation, Caries Res 11 (Suppl): 2-23. 
FDl (1982): Technical Report No. 15. An Epidemiological Index of Developmental Defects of Enamel, Int Dent / 32: 159-167.

FEJERSKOV, O.; THYLSTRUP, A.; and LARSEN, M.J. (1981): Rathonal Use of Fluorides in Caries Prevention. A Concept Based on Possible Cariostatic Mechanisms, Acta Odontol Scand 39: 241249.

GIFT, H.C. (1986): Current Utilization Patterns of Oral Hygiene Practices. In: Dental Plaque Control Measures and Oral Hygiene Practices, $H$. Löe and D.V. Kleinman, Eds., Washington, DC: IRL Press, pp. 39-71.

HENNON, D.K.; STOOKEY, G.K.; and BEISWANGER, B.B. (1977): Fluoride-Vitamin Supplements: Effects on Dental Caries and Fluorosis when Used in Areas with Suboptimum Fluoride in the Water Supply, I Am Dent Assoc 95: 965-971.

HOROWITZ, H.S.; DRISCOLL, W.S.; MEYERS, R.J.; HEIFETZ, S.B.; and KINGMAN, A. (1984): A New Method for Assessing the Prevalence of Dental Fluorosis - the Tooth Surface Index of Fluorosis, I Am Dent Assoc 109: 34-41.

KEGELES, S.S. (1963): Some Motives for Seeking Preventive Dental Care, I Am Dent Assoc 67: 90-98.

LARSEN, M.J.; RICHARDS, A.; and FEJERSKOV, O. (1985): Development of Dental Fluorosis According to Age at Start of Fluoride Administration, Caries Res 19: 519-527.

LEVINE, R.S. (1976): The Action of Fluoride in Caries Prevention: A Review of Current Concepts, Br Dent / 140: 9-14.

LEVERETT, D.H. (1982): Fluorides and Changing Prevalence of Dental Caries, Science 217: 26-30.
NARENDRAN, S.; BAGRAMIAN, R.A.; and LANG, W.P. (1987) Dental Fluorosis and Caries in a Non-fluoridated Community, J Dent Res 66: 164, Abst. No. 462.

NEWBRUN, E. (1980): Systemic Fluorides, an Overview, I Can Dent Assoc 46:31-37.

OLDAK, S.B. and LEVERETT, D.H. (1984): Dental Fluorosis in a Non-fluoridated Community, I Dent Res 63: 197, Abst. No. 239.

RADIKE, A.W. (1968): Criteria for Diagnosis of Dental Caries. In: Proceedings of the Conference on the Clinical Testing of Cariostatic Agents, Chicago: American Dental Association, pp. 8788.

RUSSELL, A.L. (1961): The Differential Diagnosis of Fluoride and Non-fluoride Opacities, I Publ Health Dent 21: 143-146.

SEGRETO, V.A.; COLLINS, E.M.; CAMANN, D.; and SMITH, C.T. (1984): A Current Study of Mottled Enamel in Texas, I Am Dent Assoc 113: 29-33.

SOPARKAR, P.M. and DePAOLA, P.F. (1985): History of Fluoride Ingestion Among Children Diagnosed with and without Fluorosis, J Dent Res 64: 226, Abst. No. 459.

SUCKLING, G.W. and PEARCE, E.I.F. (1984): Developmental Defects of Enamel in a Group of New Zealand Children: Their Prevalence and Some Etiological Factors, Community Dent Oral Epidemiol 12: 177-184.

THYLSTRUP, A.; FEJERSKOV, O.; BRUUN, C.; and KANN, J. (1979): Enamel Changes and Dental Caries in 7 Year Old Children Given Fluoride Tablets from Shortly After Birth, Caries Res 13: $265-276$. 